\title{
Method development for the influence of matrix on selected organochlorine pesticide residue analysis in surface water by GC-MS
}

\author{
C. Rimayi ${ }^{1,3}$, F. Mtunzi ${ }^{1}$, C. V. Wyk ${ }^{2}$ \& D. Odusanya ${ }^{3}$ \\ ${ }^{1}$ Department of Chemistry, Vaal University of Technology, \\ Vanderbijlpark, South Africa \\ ${ }^{2}$ Department of Biotechnology, Vaal University of Technology, \\ Vanderbijlpark, South Africa \\ ${ }^{3}$ Department of Water Affairs, Resource Quality Services (RQS), \\ Roodeplaat, Pretoria, South Africa
}

\begin{abstract}
An automated solid phase extraction (SPE) method coupled to GC-MS method for the analysis of selected organochlorine pesticides was developed and validated for the purposes of studying the matrix effects. The analytical method showed a significant degree of validity when tested against parameters such as linearity, repeatability and sensitivity. Four different reversed sorbent phases, including a Supelco LC18, Strata C18-E and Strata-X (styrene divinyl benzene) were tested for organochlorine extraction efficiency. The LC-18 proved to be the most robust and effective sorbent phase as it produced better recoveries varying from $90-130 \%$ for most analytes. It was then concluded that the method developed was suitable for further research towards the influence of the matrix on selective determination of the selected organochlorine pesticides.
\end{abstract}

Keywords: solid phase extraction (SPE), organochlorine pesticides, gas chromatography-mass spectrometry (GC-MS).

\section{Introduction}

In order to fully understand the principles behind the matrix effects in GC-MS analysis, it is of paramount importance to develop a robust and rugged validated analytical method that shows a high degree of specificity for each particular 
analyte. Validation gives an indication of the trueness of an analytical method, this will help to distinguish between the effects of the matrix on the analyte from those that may arise from random or systematic errors in the process sample handling and preparation (Quintana et al. [1]). The trueness of a method should always be assessed before it is applied for any routine sample analysis (Maroto et $a l$. [2]). Both the amount and type of matrix can affect the perceived recovery therefore it is important to effectively isolate analytes of interest from the matrix components as even the tandem (MS/MS) mode is prone to detect co-extracted matrix components (Maroto et al. [2]; Poole [3]; Fenich et al. [4]; Ruiz-Gutierrez and Perez-Camio [5]).

Solid phase extraction (SPE) is a sample preparation technique used for extracting semivolatile and non-volatile analytes from their matrices for subsequent chromatographic analysis. It is considered one of the most powerful techniques currently available for isolating trace amounts of organic compounds such as pesticides from water and other environmental samples (Saini et al. [6]; Ferrer and Barcelo [7]; Gulbakan et al. [8]). It entails the use of SPE cartridges which are packed with silica bonded to a particular analyte adsorbing phase. SPE can be compared to other extraction techniques like liquid-liquid extraction although it is advantageous in that it provides better selectivity and extraction efficiency (recovery), eliminates problems associated with incomplete phase separation and yields quantitative extractions that are easy to perform (Supelco [9]; Nema et al. [10]; Marce and Borurull [11]). Selectivity is the degree to which an extraction technique can separate the analyte of interest from its matrix (Ferrer and Barcelo [7]).

The SPE method development is targeted at developing a methodology that is specific to the analytes of interest (Verpiand et al. [12]). Accordingly, the analytes of interest in this research are the following organochlorine compounds: Pentachlorobenzene, BHC-alpha, Hexachlorobenzene, BHC-beta, Lindane (BHC gamma), Pentachloronitrobenzene, BHC-delta, Heptachlor, Aldrin, Heptachlorepoxide, Chlordane trans (gamma), Endosulfan (I) alpha, Chlordane cis (alpha), Dieldrin, 4,4-DDE, Endrin, Endosulfan (II) beta, 4,4-DDD, Endosulfan sulphate, 4,4 DDT and Mirex.

\section{Materials and methods}

Grade A volumetric flasks and pipettes, funnels, spatula and Pasteur pipettes were used for reagent preparation. Methanol, Dichloromethane, Toluene, Acetone, Hexane, SPE cartridges, collection vials, $2 \mathrm{ml}$ vials, caps, inserts, test tubes and nitrogen gas were also used in the SPE method development. A Mettler Loledo AX105 Delta Range ${ }^{\circledR}$ analytical balance was used to weigh the standards to four decimal places.

\section{Quality control}

All volumetric flasks and pipettes were calibrated before use. Analytical balances were calibrated annually and verified daily using standard reference 
masses. Grade A volumetric glassware and analytical (pesticide) grade reagents were also used for the entire analysis with a purity $>99 \%$. All cartridge testing for SPE method development was done in at least duplicate analysis. Deionised ultrapure water was sourced from a Millipore Milli-Q system. The water was passed through an organic compound scavenger resin bed before passing to the Milli-Q system. The certified pesticide neat standards had a purity of at least 98.5\% (obtained from Dr Ehrenstorfer and Chemservice) and 100mg/l stock solution and subsequent cocktails were prepared in toluene and stored at $\leq-18^{\circ} \mathrm{C}$. Spiking solutions were prepared in acetone. Temperatures for the laboratory atmosphere and freezers were monitored daily.

\section{GCMS configuration}

An Agilent Technologies 6890 GC coupled to an Agilent Technologies 5975 Quadrupole Mass Selective Detector was used for analysis using a $30 \mathrm{~m} \mathrm{x}$ $0.25 \mathrm{~mm} \times 0.25 \mu \mathrm{m}$ DB-5MS column with stationary phase $5 \%$ phenyl and $95 \%$ dimethylpolysiloxane. The mobile phase of choice used was $99.999 \%$ helium gas supplied by Airliquide South Africa.

Total runtime for the analysis was 31.87 minutes with initial temperature of $70^{\circ} \mathrm{C}$ and hold time of 2 minutes. Ramp 1 was $25^{\circ} \mathrm{C} / \mathrm{min}$ to $150^{\circ} \mathrm{C}$, with no hold time. Ramp 2 was $3^{\circ} \mathrm{C} / \mathrm{min}$ to $200^{\circ} \mathrm{C}$, with no hold time and ramp 3 was $8^{\circ} \mathrm{C} / \mathrm{min}$ to $280^{\circ} \mathrm{C}$ with no hold time. A constant pressure of $129.9 \mathrm{KPa}$ was maintained with an average velocity of $50 \mathrm{~cm} /$ second. Data was analysed using chemstation software from Agilent Technologies. A $1 \mu \mathrm{l}$ volume of sample was injected using an ALS autosampler.

\section{Peak identification}

To identify the peaks of interest, $10 \mathrm{mg} / 1(\mathrm{ppm})$ neat standards were injected to determine the retention time for each analyte. To increase the specificity of the analytical method, particularly in the presence of a matrix, Selective Ion Monitoring (SIM) mode was configured into the GCMS. An average of 4 major ion fragments from each analyte were selected for use in identification of the compounds, using criteria of a balance between the highest mass and abundance, since each compound has a specific ion spectrum.

All the peaks from the $1 \mathrm{mg} / 1$ cocktail mix having been identified, calibration standards were then made up by serial dilution for validating the GCMS instrument method, using the calibration levels: $1 \mathrm{mg} / 1,0.5 \mathrm{mg} / 1,0.25 \mathrm{mg} / 1$, $0.125 \mathrm{mg} / 1,0.0625 \mathrm{mg} / 1,0.0313 \mathrm{mg} / 1,0.0156 \mathrm{mg} / 1$ and $0.0078 \mathrm{mg} / \mathrm{l}$. The $1 \mathrm{mg} / \mathrm{l}$ cocktail was also used to test SPE cartridges for efficiency of extraction and determination of validation criteria for the SPE method.

\section{Solid phase extraction}

The solid phase extraction was performed using an automated instrument, the Gilson GX-271 liquid handling instrument. Sample preparation is the most 


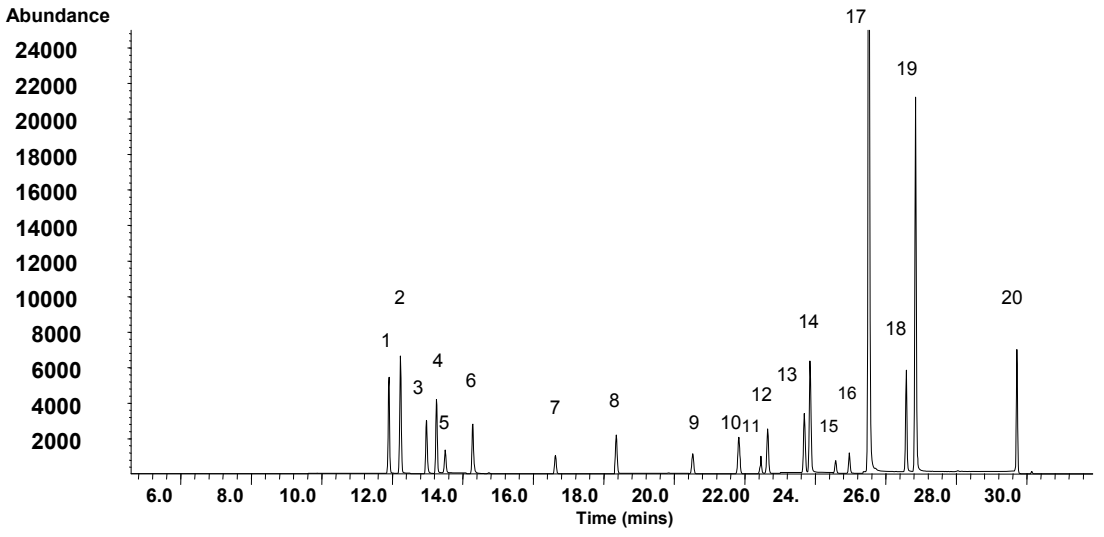

1. BHC alpha 2. Hexachlorobenzene 3. BHC beta 4. BHC gamma 5. Pentachloronitrobenzene 6 . BHC delta

7. Heptachlor 8. Aldrin 9. Heptachlor epoxide 10. Chlordane trans (gamma) 11. Endosulphan alpha

12. Chlordane cis 13. Dieldrin 14. 4,4' DDE 15. Endrin 16. Endosulphan beta 17. 4,4' DDD

19. Endosulphan sulphate 19.4.4'DDT 20. Mirex.

Figure 1: SIM chromatogram of organochlorine cocktail.

tedious and time consuming step and a possible source of errors (Huck and Bonn [13]; He et al. [14]). Automated solid phase extraction was employed as it is more rapid, precise and accurate compared to the conventional manual SPE extraction (Parker et al. [15]; Rossi and Zhang [16]).

\subsection{SPE cartridges used}

\subsubsection{Strata-X (500mg)}

The Strata-X is a reversed phase bed cartridge suitable for the extraction of polar and non polar analytes with hydrocarbon and aromatic groups which form a surface modified styrene divinyl benzene group. This gives it an advantage over other sorbents in that it is deconditioning resistant and has better selectivity for polar and non polar compounds (Countryman et al. [17]). The styrene divinyl structure also has the advantage of selective interaction with aromatic rings as those in DDT through formation of specific $\pi-\pi$ interactions (Ferrer and Barcelo [7]; Marce and Borurull [11]). Reversed phase cartridges are frequently used in environmental chemistry to extract organic substances from aqueous samples such as water (Saini et al. [6]). The cartridge contained a bed mass of 500mg and is suitable for the analysis of Organochlorine compounds and the functional group is displayed below in figure 2 .

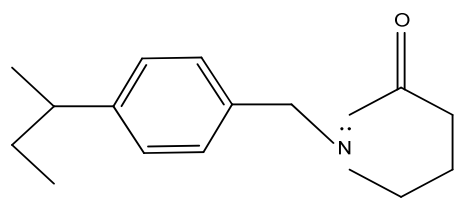

Figure 2: $\quad$ Functional group of Strata-X. 


\subsubsection{LC-18 (Supelco) (200mg)}

The LC-18 (Supelco) cartridge consists of an octadecyl bonded endcapped silica reversed phase bed. It is suitable for non polar to moderately polar compounds such as the organochlorine compounds under study. The hydrophilic silanol groups at the surface of the raw silica packing have been chemically modified with hydrophobic alkyl or aryl functional groups by reaction with the corresponding silates (Supelco [9]). The functional group is displayed below in figure 3 .

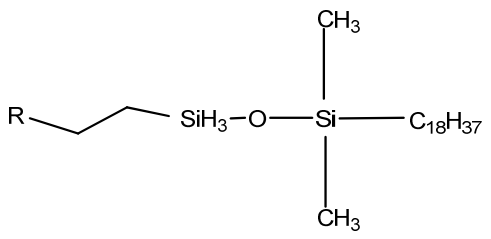

Figure 3: $\quad$ Functional group of LC-18 (Supelco).

\subsubsection{Strata C18-E (200mg) and Strata C18- E (500mg)}

The Strata C18-E (S C18-E) cartridge used was a reversed phase absorbent with a hydrocarbon and aromatic functional group. Its retention mechanism is through hydrophobic interactions, hydrogen bonding and aromatic interactions (Pavlovic et al. [18]; Li et al. [19]; Fontanels et al. [20]). A 200mg and a 500mg sorbent bed mass were used for the method development, particularly to test the effect of increasing the sorbent bed mass on analyte retention. The two functional groups of the Strata C18- E cartridge sorbent bed shown below in figure 4;

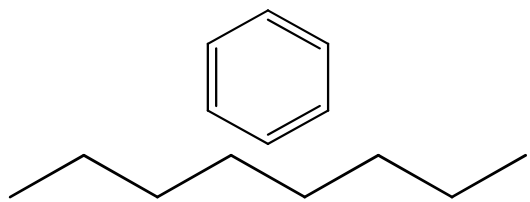

Figure 4: Functional groups of Strata C18- E.

\subsection{SPE test procedure}

The automated SPE method development was designed to configure the best procedure to use for the extraction of the organochlorine compounds under study. The test procedure considered the following parameters;

1) Sorbent (solid phase) choice

2) Sorbent treatment

3) Sorbent mass

4) Sample pre-treatment

5) Sample volume and flow mechanism

6) Solvent choice 
The Gilson GX-271 liquid handling instrument is capable of performing the following cartridge treatment steps:

1) Conditioning cartridges: this is done to activate the sorbent bed

2) Loading cartridges: this is done to introduce the analytes to the sorbent bed where they are adsorbed.

3) Drying cartridges: this is done to remove any water remaining on the sorbent bed and prevent the introduction of water to the elute.

4) Eluting cartridges: this is the process of desorbing the adsorbed analytes by adding a polar solvent that washes the analytes from the sorbent bed (Poole et al. [21]).

For effective mass transfer of analytes onto the sorbent a consistent flow rate applied at low pressure was used (Nema et al. [10]). The Gilson GX-271 liquid handling instrument utilises positive pressure elution which makes it increasingly easy to control flow rates (Gilson [22]). Extensive cleanup of extracts may result in the partial loss of some compounds, hence this method development was aimed at retaining as much analyte as possible within the final extract (Hajslova et al. [23]).

\section{Results and discussion}

\subsection{GCMS instrument method validation}

Method validation is essential as it confirms that an analytical method is effective in measuring the parameters it is intended to measure. Successful validation of the GC-MS method developed confirmed that the methods, procedures and protocols applied in the analysis were reliable and accurate and as a result valid conclusions were postulated.

\subsection{Validation parameters}

For the purposes of method validation the parameters tested were linearity, working range, repeatability, limits of detection, limits of quantitation and analysis of variance (ANOVA) as shown in Table 1.

The table below shows the calibration range in which acceptable accuracy, linearity and precision can be obtained.

Table 1 also displays the linear regression for the calibration curves, repeatability, Limits of Detection (LOD) and Limits of Quantification (LOQ). However, from the table above DDT showed no significant linearity and therefore a quadratic fit was used. BHC-delta and Lindane (BHC gamma) showed the lowest LOD's with DDE 4, 4', and Endosulfan beta showing the broadest linear ranges of $1 \mathrm{mg} / 1$ to $0.0156 \mathrm{mg} / \mathrm{l}$.

Hypothesis testing was done using the analysis of variance (ANOVA) F-test with the null hypothesis $\mathrm{H}_{0}=$ there is no significant linearity in the selected organochlorines at a $95 \%$ confidence level. 
Table 1: Validation parameters for selected organochlorine compounds $(\mathrm{n}=11)$.

\begin{tabular}{|c|c|c|c|c|c|}
\hline $\begin{array}{l}\text { Compound } \\
\text { Name }\end{array}$ & $\begin{array}{c}\text { Linear } \\
\text { Range }(\mathrm{mg} / \mathrm{l})\end{array}$ & $\mathrm{R}^{2}$ & $\begin{array}{l}\text { Repeatability } \\
\text { (RSD\%) }\end{array}$ & $\begin{array}{l}\mathrm{LOD} \\
(\mathrm{mg} / \mathrm{l})\end{array}$ & $\begin{array}{c}\mathrm{LOQ} \\
(\mathrm{mg} / \mathrm{l})\end{array}$ \\
\hline Aldrin & $1-0.0313$ & 0.9990 & 6.45 & 0.038 & 0.125 \\
\hline BHC-alpha & $1-0.125$ & 0.9984 & 9.63 & 0.062 & 0.205 \\
\hline BHC-beta & $1-0.0313$ & 0.9985 & 3.92 & 0.060 & 0.201 \\
\hline BHC-delta & $0.5-0.0313$ & 0.9980 & 4.59 & 0.018 & 0.060 \\
\hline $\begin{array}{l}\text { Chlordane cis } \\
\text { (alpha) }\end{array}$ & $1-0.0313$ & 0.9995 & 3.22 & 0.048 & 0.161 \\
\hline $\begin{array}{c}\text { Chlordane, } \\
\text { trans (gamma) }\end{array}$ & $1-0.125$ & 0.9993 & 3.23 & 0.049 & 0.162 \\
\hline DDD 4,4' & $1-0.125$ & 0.9982 & 5.93 & 0.083 & 0.277 \\
\hline DDE $4,4^{\prime}$ & $1-0.0156$ & 0.9993 & 4.31 & 0.068 & 0.228 \\
\hline DDT $4,4^{\prime}$ & Non linear & Non linear & 5.25 & 0.078 & 0.261 \\
\hline Dieldrin & $0.5-0.0313$ & 0.9999 & 3.75 & 0.025 & 0.082 \\
\hline $\begin{array}{l}\text { Endosulfan } \\
\text { alpha }\end{array}$ & $1-0.0313$ & 0.9986 & 4.23 & 0.047 & 0.155 \\
\hline $\begin{array}{c}\text { Endosulfan } \\
\text { beta }\end{array}$ & $1-0.0156$ & 0.9990 & 2.65 & 0.019 & 0.063 \\
\hline $\begin{array}{c}\text { Endosulfan } \\
\text { SO4 }\end{array}$ & $1-0.25$ & 0.9988 & 7.17 & 0.027 & 0.091 \\
\hline Endrin & $0.5-0.125$ & 0.9994 & 5.81 & 0.021 & 0.071 \\
\hline Heptachlor & $0.5-0.125$ & 0.9980 & 5.17 & 0.037 & 0.123 \\
\hline $\begin{array}{l}\text { Heptachlor- } \\
\text { epoxide }\end{array}$ & $0.5-0.0156$ & 0.9991 & 4.39 & 0.029 & 0.095 \\
\hline $\begin{array}{l}\text { Hexachloro- } \\
\text { benzene }\end{array}$ & $0.5-0.0625$ & 0.9983 & 2.75 & 0.023 & 0.077 \\
\hline Lindane & $0.5-0.0313$ & 0.9982 & 4.20 & 0.018 & 0.059 \\
\hline Mirex & $1-0.125$ & 0.9995 & 4.41 & 0.056 & 0.187 \\
\hline
\end{tabular}

$\mathrm{n}=$ number of replicates.

The decision rule used: If F-calculated $>$ F-critical $=$ reject $\mathrm{H}_{0}$, led to the decision that there was significant linearity for all Organochlorine compounds.

\section{Results of real sample and blank analysis}

The matrix is a burden on pesticide residue analysis (Poole [3]). Unfortunately, it is impossible to completely eliminate the matrix from a real sample matrix in order to isolate the analyte of interest. Dedicated SPE application techniques have been developed to give extracts with comparatively low matrix burden but several problems still arise in GC-MS pesticide residue analysis of the matrix based extracts (Poole [3]). One set of the four test cartridges was loaded with 
$10 \mathrm{ml}$ spiked real samples (s) and another set with $10 \mathrm{ml}$ blank deionised water samples (b) using the following developed optimised conditions.

1) Condition $6 \mathrm{ml} \mathrm{methanol} \mathrm{with} \mathrm{flow} \mathrm{rate} 6 \mathrm{ml} / \mathrm{min}$.

2) Load $10 \mathrm{ml}$ sample with flow rate $1.5 \mathrm{ml} / \mathrm{min}$.

3) Dry using nitrogen gas for 2 minutes with flow rate $6 \mathrm{ml} / \mathrm{min}$.

4) Elute with $6 \mathrm{ml} \mathrm{DCM}$ with rate $1.5 \mathrm{ml} / \mathrm{min}$.

The results below indicate that the LC-18 cartridge produced the best real sample recoveries which were acceptable for most analytes as they were in the target range of $100 \pm 30 \%$ recovery.

Figure 5 also shows that the real sample matrix samples seemed to exhibit matrix induced enhanced chromatographic effect as all but one of the analytes produced recoveries greater than $100 \%$.

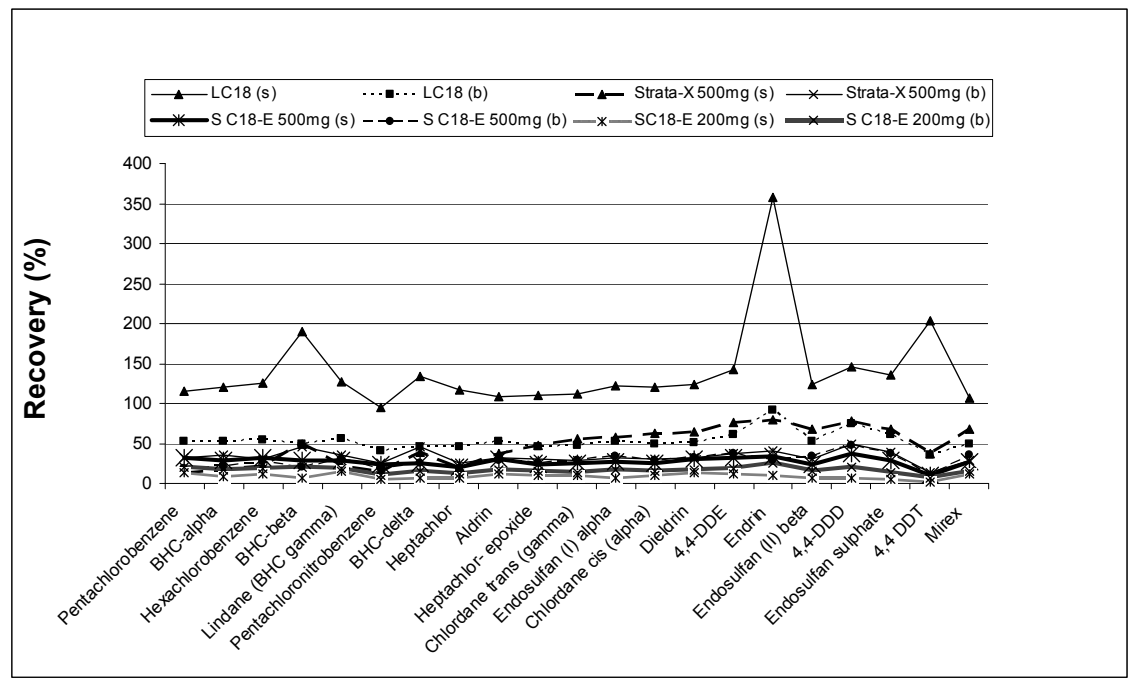

Figure 5: Recovery of spiked real sample and blank water.

Other cartridges produced recoveries of less than $100 \%$ for both the real sample and blank determinations. This indicates that there was a matrix induced diminished chromatographic response. It is not unusual to obtain recoveries as high as $>200 \%$ in pesticide residue analysis in the presence of a real sample matrix as many labs worldwide have documented such cases (Hajslova et al. [23]).

\section{Conclusions}

The method developed for the analysis of the selected organochlorine pesticides showed a significant degree of validity in terms of trueness. Most validation criteria such as repeatability, linearity, sensitivity and ANOVA were met. The 
LC-18 cartridge proved to be the most robust for the analysis of the selected organochlorine pesticides as it produced better recoveries overall, even when significant changes were made to the sample preparation procedure. The method development has clearly shown that the matrix does have an effect on the quantitation and detection of analytes although the effects of the matrix were not the focal point of this paper. Automation of SPE has proved to be an important aspect of SPE analysis and is equally as beneficial as the use of a GC automatic sample injector in terms of drastically increasing precision and accuracy and also substantially reducing the chances of human error. However it should be noted that the issue of defining acceptable recoveries remains a controversial and subjective issue where matrix based extractions are involved.

\section{References}

[1] Quintana, J., Marti I. \& Ventura F., Monitoring of pesticides in drinking and related waters in NE Spain with a multi residue SPE-GC-MS method including an estimation of uncertainty of the analytical results, Journal of Chromatography A 938, Department of Organic Analytical Chemistry: Barcelona pp. 1-8, 2001.

[2] Maroto, A., Boque, R., Riu, J. \& Rius, F. X., Measurement uncertainty in analytical methods in which trueness is assessed from recovery assays, Journal of Chromatography A 440, Department of analytical Organic Chemistry: Spain pp. 171-172, 2000.

[3] Poole, C. F., Matrix induced response enhancement in pesticide residue analysis by gas chromatography, Journal of Chromatography A 1158, Department of Chemistry, Wayne State University: Detroit pp. 241-249, 2007.

[4] Fenich, A. G., Martinez, J. L., Moreno, J. L. F. \& Romero-Gonzales, R., Compensation for matrix effects in gas chromatography- tandem mass spectrometry using a single point standard addition, Journal of Chromatography A 1216, Department of Analytical Chemistry, University of Almera: Spain, pp. 4798-4802, 2009.

[5] Ruiz-Gutierrez, V \& Perez-Camio, M. C., Update on solid phase extraction for the analysis of lipid classes and related compounds, Journal of Chromatography A 885: Spain pp. 321-323, 2000.

[6] Saini, G., Wiest, L. A., Herbert, D., Biggs, N., Dadson, A., Vail, M. A. \& Linford, M. R. C18, C8 and perfluro reversed phases on diamond for solid phase extraction, Journal of Chromatography A 1216, US Synthetic Corporation: USA, pp. 3587-3589, 2008.

[7] Ferrer, I \& Barcelo, D., Validation of new solid-phase extraction materials for the selective enrichment of organic contaminants from environmental samples, Trends in Analytical Chemistry 18(3), Department of Environmental Chemistry: Barcelona pp. 181-182, 1999. 
[8] Gulbakan, B., Uzin, C., Celikbicak, O., Guven, O. \& Salih, B., Solid phase extraction of organochlorine pesticides with modified poly(styrenedivinylbenzene) microbeads using home-made solid phase extraction syringes. Relative and Functional Polymers 68, Hacettepe University: Turkey, pp. 580-582, 2007.

[9] Supelco: Guide to Solid Phase Extraction, bulletin 910, pp.1-12, SigmaAldrich:USA. www.sigmaaldrich.com/etc/medialib/docs/Supelco/Bulletin /4538.Par.0001.File.tmp/4538.pdf

[10] Nema, T., Chan, E. C. Y. \& Ho P. C., Application of silica-based monolith as solid phase extraction cartridge for extracting polar compounds from urine. Talanta 82, Department of Pharmacy, National University of Singapore: Singapore, pp. 488-490, 2010.

[11] Marce, R. M. \& Borurull, F., Solid-phase extraction of polycyclic aromatic compounds, Journal of Chromatography A 885: Spain, pp. 274-277, 2000.

[12] Verpiand, M., Roberts, R. \& Javadi, G., The art of SPE Method Development. Technical article Part I Varian: California, 2007.

[13] Huck, C. W. \& Bonn, G. K., Recent developments in polymer-based sorbents for solid phase extraction, Journal of Chromatography A 885, Institute of analytical Chemistry and Radiochemistry, Leopold-Franzens University: Austria, pp. 50-55, 2000.

[14] He, C., Long, Y., Pan, J., Li, F. \& Liu, F., Application of molecularly imprinted polymers to solid-phase extraction of analytes from real samples, Journal of Biochemistry and Biophysics Methods 70, China, pp. 134, 2006.

[15] Parker, D. T., Surendran, N., Stewart, B. H. \& Rossi, D. T., Automated sample preparation for drugs in plasma using a solid phase extraction workstation, Journal of Pharmaceutical and Biomedical Analysis 17, Parke-Davis Pharmaceutical Research: USA, pp. 851-861, 1997.

[16] Rossi, D. T. \& Zhang, N., Automating Solid-phase extraction: current aspects and future prospects. Journal of Chromatography A, 885, Bioanalytical Core group: USA, pp. 97-99, 2000.

[17] Countryman, S., Shock, D. \& Teushcer, J., SPE Applications, Solid phase extraction of Nitroanilines from water. A comparison of Strata X vs styrene-divinylbenzene polymeric sorbents, TN-003, Phenomenox Inc: USA.

[18] Pavlovic, D. M., Babic, S., Dolar, D., Asperger, D., Kosutic, K., Horvat, A. J. M. \& Kastelan-Macan, M., Development and optimization of the SPE procedure for determination of pharmaceuticals in water samples by HPLCdiode array detection, Journal of Separation Science 33(2), Department of Analytical Chemistry: Croatia, pp. 259-261, 2009.

[19] Li, K. M., Rivory, L. P. \& Clarke, S. J., Solid-Phase Extraction (SPE) techniques for sample preparation in clinical and pharmaceutical analysis: A brief overview, Current Pharmaceutical analysis 2(2), Institute of Biomedical Research: Australia pp. 97-107, 2006. 
[20] Fontanels, N., Marce, R. M. \& Borull, F., New hydrophilic materials for solid phase extraction, Trends in Analytical Chemistry 24(5), Department of Analytical Chemistry, Tarragona: Spain, pp. 398-401 2005.

[21] Poole, C. F., Gunatilleka, A. D. \& Sethuraman, R., Contributions of theory to method development in solid-phase extraction, Journal of Chromatography A 885, Department of Chemistry, Wayne State University: Detroit, pp. 17-20, 2000.

[22] Gilson Inc. Solid phase extraction solutions. USA. 2006. http://www.johnmorris.com.au/files/product/attachments/3429/239358_ma nual_instr.pdf

[23] Hajslova, J., Holadova, K., Kocourek, V., Poustka, J., Godula, M., Cuhra, P. \& Kempny, M., Matrix induced effects: a critical point in the gas chromatographic analysis of pesticide residues, Journal of Chromatography $A$ 800, Czech Agriculture and Food Inspection: Czech Republic, pp. 283286, 1997. 